\title{
Irrelevance of Conjectural Variation in a Mixed Duopoly: The Case of Relative Performance and Consistent Conjectures*
}

\author{
Yasuhiko Nakamura \\ College of Economics, Nihon University, Chiyoda, Japan \\ Email: yasuhiko.r.nakamura@gmail.com
}

Received July 6, 2013; revised August 15, 2013; accepted 21, 2013

Copyright (C) 2013 Yasuhiko Nakamura. This is an open access article distributed under the Creative Commons Attribution License, which permits unrestricted use, distribution, and reproduction in any medium, provided the original work is properly cited.

\begin{abstract}
This study explores the equilibrium outcomes in the contexts of quantity-setting and price-setting mixed duopolies with consistent conjectures of both the social welfare maximizing public firm and the relative profit maximizing private firm. Similar to the private duopoly composed of only relative profit maximizing firms, we show that in the mixed duopoly, the equilibrium outcomes in the quantity-setting competition with the consistent conjectures of both firms are equivalent to those in the price-setting competition with the consistent conjectures of both firms.
\end{abstract}

Keywords: Mixed duopoly; Relative Profit Maximization; Conjectural Variation; Consistent Conjecture JEL Classification: L20, L32, D43

\section{Introduction}

In the context of a mixed duopolistic market with the differentiated and substitutable goods, this study addresses the problem of whether or not the consistent conjectures of the public firm and the private firm yield the same equilibrium outcomes in a quantity-setting competition and a price-setting competition. The topic of conjectural variations in oligopolistic markets has been investigated for a long time; for example, Bresnahan [1], Perry [2], Boyer and Moreaux [3], Tanaka [4], and Tanaka [5] considered the influence of the conjectural variations of firms on the equilibrium market outcomes in several economic contexts. ${ }^{1}$ More recently, in a private duopoly with linear demand functions and constant marginal cost functions which is composed of the two symmetric private firms, Tanaka [6] showed that firms' equilibrium output and the price levels in the Cournot equilibrium under their relative profit maximization are equal to their equilibrium output and prices in the Bertrand equilibrium under their relative profit maximization. ${ }^{2}$ Furethermore, in a private duopoly wherein symmetric private firms maximize their relative profits, Tanaka [8]

\footnotetext{
*We are grateful for the financial support from KAKENHI (25870113) All remaining errors are our own.

${ }^{1}$ In particular, Perry [2] showed that each firm's competitive conjecture is the unique consistent conjecture in a private duopoly with a homogeneous good and its constant marginal cost function.
}

found that 1) their conjectural variations are irrelevant to the equilibrium outcome, and both their quantity setting behaviors and their price setting behaviors are equivalent to any of their conjectural variations; and 2) all the conjectural variations common to both the firms are consistent.

On the other hand, the relative profit approach has been adopted in many modern theoretical oligopolistic works. In the context of evolutionary economics `a la Schaffer [9], Vega-Redondo [10] found that each firm's adoption of its relative profit maximizing behavior yields the Walrasian equilibrium in the general equilibrium framework. Furthermore, Lundgren [11] presented a new economic method for preventing incentives for collusion by making managerial compensation which depends on relative profits rather than absolute profits. Kockesen, et al. [12] derived the condition that a firm with interdependent preferences (i.e., the relative profit preference) obtains a strictly higher profit than an independent (i.e., the absolute profit preference) firm in any equilibrium.

\footnotetext{
${ }^{2}$ In addition, Tanaka [7] found that in a private duopoly with linear demand and constant marginal cost functions, when the two symmetric private firms maximize their relative profits, the choices of their strategic variables are irrelevant to the outcome of the game in the sense that the equilibrium outcomes are the same in all three types of market structure, and then any combination of choices of strategic variables by the firms comprises a subgame perfect equilibrium in the two stage game.
} 
Most recently, Matsumura and Matsushima [13] investigated the relationship between the degree of competition and the stability of collusive behavior by introducing the element of relative performance to the objective functions of firms and showed that an increase in the degree of competition destabilizes collusion ${ }^{3}$.

Given the importance of both the relative profit approach and conjectural variations in an oligopolistic market, the purpose of this paper is to ascertain whether or not the irrelevance result that the equilibrium market outcomes in the quantity-setting competition are equivalent to those in the price-setting competition in a mixed duopoly with differentiated and substitutable goods and with the consistent conjectural variations of both the social welfare-maximizing public firm and the relative profit-maximizing private firm. In this paper, by following Tanaka [8], we consider a mixed duopoly with linear demand functions and constant marginal cost functions. Under the above assumptions, we show that in a mixed duopoly with the consistent conjectures of both the social welfare-maximizing public firm and the relative profit maximizing private firm, the equilibrium market outcomes in the quantity-setting competition including their output and price levels, absolute profits, consumer surplus, and social welfare are the same as those in the price-setting competition ${ }^{4}$. Thus, in a mixed duopoly wherein it is possible for both the public firm and the private firm to react consistently its opponent firm's strategic variable, i.e., price or output levels, we must refrain from making the shortsighted judgment that the price-setting competition should be used rather than the quantity-setting competition, and vice versa.

The remainder of this paper is organized as follows. In Section 2, we formulate the basic model employed in this paper. In Section 3, we derive the equilibrium outcomes in both the quantity-setting competition and the pricesetting competition with differentiated and substitutable goods wherein the public and private firms consistently react to their respective opponent firm's strategic variable. Section 4 concludes with several remarks.

\section{Model}

We consider a mixed duopolistic market composed of one social welfare maximizing public firm (firm 0 ) and one relative profit-maximizing private firm (firm 1). We use $q_{i}$ and $p_{i}$ to represent firm $i$ 's output and price levels,

\footnotetext{
${ }^{3}$ Moreover, existing works using the relative performance approach in the context of a mixed duopoly with one welfare maximizing public firm and one relative profit-maximizing private firm include Nakamura and Saito [14], who investigated each firm's capacity choice in the quantity-setting competition, and Nakamura and Saito [15], who considered each firm's capacity choice in price-setting competition.

${ }^{4}$ In the model of this paper, this result is satisfied in the standard mixed duopoly wherein the private firm maximizes its absolute profit since we allow the case wherein the degree of importance of its relative performance is zero.
}

respectively, $(i=0,1)$. We adopt the constant marginal cost function, which $c$ is a common marginal cost between firms 0 and 1 , similar to Tanaka [8].

In addition, we assume that firms 0 and 1 incur no fixed costs. We use $\delta_{i}^{q q}$ and $\delta_{i}^{p p}$ to denote firm $i$ 's consistent conjectural variation and we suppose that $-1<\delta_{i}^{q q}<1$ and $-1<\delta_{i}^{p p}<1,(i=0,1)$. On the basis of the assumption of Tanaka [8], we employ the following inverse demand function of the goods produced by firm $i$ 'a la Singh and Vives [16]:

$$
p_{i}\left(q_{i}, q_{j}\right)=a-q_{i}-b q_{i}, \quad i, j=0,1 ; i \neq j
$$

where $a>c, 0$ and $0<b<1^{5}$. This inverse demand function results from the following representative consumer's utility:

$$
U\left(q_{0}, q_{1}\right)=a\left(q_{0}+q_{1}\right)-\frac{q_{0}^{2}+2 b q_{0} q_{1}+q_{1}^{2}}{2}+m,
$$

where $m$ denotes the income of the representative consumer. Furthermore, the ordinary demand functions for the goods of firms 0 and 1 are obtained from the above inverse demand functions as follows:

$$
q_{i}=\frac{a(1-b)-p_{i}+b p_{j}}{1-b^{2}}, \quad i, j=0,1 ; i \neq j .
$$

Consumer surplus is expressed as the representative consumer's utility as follows:

$C S=U\left(q_{0}, q_{1}\right)-p_{0} q_{0}-p_{1} q_{1}$, whereas producer surplus is given by the sum of the profits of firms 0 and 1 , $\pi_{0}+\pi_{1}$. Finally, we suppose that social welfare $W$ is defined as the sum of the consumer surplus and the producer surplus ${ }^{6}$, implying that $W=C S+\left(\pi_{0}+\pi_{1}\right)$.

\section{Equilibrium Analysis}

In this section, we derive the equilibrium outcomes with public firm 0 and private firm 1 in the contexts of both the quantity-setting competition and the price-setting competition with consistent conjectures for both firms.

\subsection{Quantity-Setting Framework}

In this subsection, we consider the situation wherein the

\footnotetext{
${ }^{5}$ The value of $b \in(0,1)$ indicates that the relation between the goods of firms 0 and 1 are substitutable. Moreover, the assumption that $a>c \geq 0$ is made in order to ensure the non-negativity of all equilibrium outcomes.

${ }^{6}$ Similar to Matsumura and Okamura [17], Nakamura and Saito [14], and Nakamura and Saito [15], we consider social welfare not as the sum of consumer surplus and the relative profits of firms 0 and 1 but as the sum of consumer surplus and the profits of firms 0 and 1. Firms' CEOs frequently emphasize the relative performance of their firms rather than the absolute performance of their firms since relatively good performance increases current and future income. However, we regard such an increase of income as a simple income transfer. For this reason, we suppose that the social welfare in this paper is equal to the sum of consumer surplus and the profits of firms 0 and 1 .
} 
strategic variables of firms 0 and 1 are their output levels. The objective functions of firms 0 and 1 are given as follows:

$$
\begin{aligned}
& V_{0}^{q q}\left(q_{0}, q_{1}\right)=W\left(q_{0}, q_{1}\right)=a\left(q_{0}+q_{1}\right) \\
& -\frac{2 c q_{0}+q_{0}^{2}+2 c q_{1}+2 b q_{0} q_{1}+q_{1}^{2}}{2}+m, \\
& V_{1}^{q q}\left(q_{0}, q_{1}\right)=\pi_{1}\left(q_{0}, q_{1}\right)-\alpha \pi_{0}\left(q_{0}, q_{1}\right) \\
& =\left(a-c-b q_{0}-q_{1}\right) q_{1}-q_{0}\left(a-c-q_{0}-b q_{1}\right) \alpha
\end{aligned}
$$

where $\alpha \in[0,1)^{7}$.

Firm 0 decides its output level in order to maximize $V_{0}^{q q}$, assuming that the reaction of the output level of firm 1 to the output level of firm 0 is given as follows:

$$
\frac{\partial q_{1}}{\partial q_{0}}=\delta_{0}^{q q}
$$

On the other hand, firm 1 decides its output level in order to maximize $V_{1}^{q q} \quad 1$ assuming that the reaction of the output level of firm 0 to the output level of firm 1 is given as follows:

$$
\frac{\partial q_{0}}{\partial q_{1}}=\delta_{1}^{q q}
$$

The first-order conditions of firms 0 and 1 in the quantity-setting market competition are given, and their real reaction functions are obtained as follows: ${ }^{8}$

$$
\begin{aligned}
& \frac{\partial V_{0}^{q q}}{\partial q_{0}}=a-c-q_{0}-b q_{1}+a \delta_{0}-c \delta_{0}-b q_{0} \delta_{0}-q_{1} \delta_{0}=0 \\
& \Leftrightarrow q_{0}\left(q_{1}\right)=\frac{a\left(1+\delta_{0}\right)-c-c \delta_{0}-b q_{1}-q_{1} \delta_{0}}{1+b \delta_{0}},
\end{aligned}
$$

$$
\begin{aligned}
& \frac{\partial V_{1}^{q q}}{\partial q_{1}}=a-b q_{0}-2 q_{1}+b q_{0} \alpha-b q_{1} \delta_{1}-a \alpha \delta_{1} \\
& \quad+2 q_{0} \alpha \delta_{1}+b q_{1} \alpha \delta_{1}-c\left(1-\alpha \delta_{1}\right)=0 \\
& \Leftrightarrow q_{1}\left(q_{0}\right)=\frac{a\left(1-\alpha \delta_{1}\right)-c+c \alpha \delta_{1}-q_{0}\left(b-b \alpha-2 \alpha \delta_{1}\right)}{2+b(1-\alpha) \delta_{1}} .
\end{aligned}
$$

From the real reaction function of the output level of firm $i$ to the output level of firm $j$, we obtain the following result $(i, j=0,1 ; i \neq j)$ :

$\frac{\partial q_{0}}{\partial q_{1}}=-\frac{b+\delta_{0}}{1+b \delta_{0}}$, and $\frac{\partial q_{1}}{\partial q_{0}}=-\frac{b-b \alpha-2 \alpha \delta_{1}}{2+b(1-\alpha) \delta_{1}}$, respectively.

The conditions of the consistency of the conjectural variations of firms 0 and 1 are, respectively,

$$
\left\{\begin{array}{l}
-\left(b+\delta_{0}\right) /\left(1+b \delta_{0}\right)=\delta_{1}, \\
-\left[b-b \alpha-2 \alpha \delta_{1}\right] /\left[2+b(1-\alpha) \delta_{1}\right]=\delta_{0},
\end{array}\right.
$$

yielding

$$
\begin{aligned}
& \delta_{0}^{q q}=-\frac{b^{2}(1-\alpha)+2\left(1-\sqrt{1-b^{2}}\right) \alpha}{b\left(1+\sqrt{1-b^{2}}+\alpha-\sqrt{1-b^{2}} \alpha\right)}, \\
& \delta_{1}^{q q}=\frac{-1+\sqrt{1-b^{2}}}{b} .
\end{aligned}
$$

The above values of firms 0 and 1 are the equilibrium consistent conjectures in the quantity-setting competition under the assumption that $\delta_{0}^{q q} \in(-1,1)$ and $\delta_{1}^{q q} \in(-1,1)$. Thus, the equilibrium output levels and price levels of firms 0 and 1 under the assumption that $\delta_{0}=\delta_{0}^{q q}$ and $\delta_{1}=\delta_{1}^{q q}$ are obtained as follows:

$$
\begin{aligned}
& q_{0}^{q q}= \\
& \frac{(a-c)\left\{b^{3}(1-\alpha)+2 b\left(1-\sqrt{1-b^{2}}\right) \alpha+4\left(1-\sqrt{1-b^{2}}\right) \alpha^{2}+b^{2}\left[2\left(1+\sqrt{1-b^{2}}\right)+3\left(1-\sqrt{1-b^{2}}\right) \alpha+\left(3-\sqrt{1-b^{2}}\right) \alpha^{2}\right]\right\}}{2(1+b)\left\{4\left(1-\sqrt{1-b^{2}}\right) \alpha^{2}+b^{2}(1-\alpha)\left[1+\sqrt{1-b^{2}}+\left(3-\sqrt{1-b^{2}}\right) \alpha\right]\right\}} \\
& \frac{q_{1}^{q q}=}{2(1+b)\left\{4\left(1-\sqrt{1-b^{2}}\right) \alpha^{2}+b^{2}(1-\alpha)\left[1+\sqrt{1-b^{2}}+\left(3-\sqrt{1-b^{2}}\right) \alpha\right]\right\}}
\end{aligned}
$$

and

\footnotetext{
${ }^{7}$ As indicated in Matsumura and Matsushima [13], if we adopt the sales delegation approach in Fershtman and Judd [18], Sklivas [19], and Vickers [20] and replace each firm's sales with the (negative) profit of the opponent firm, as in their models, it would use a positive value of $\alpha$. Moreover, for the technical reason that all equilibrium outcomes of firms 0 and 1 must be positive, throughout this paper, we adopt their common positive values of a following Matsumura and Matsushima [13], Nakamura and Saito [14], and Nakamura and Saito [15].

${ }^{8}$ The second-order conditions of firms 0 and 1 are satisfied.
} 


$$
\begin{aligned}
& {\left[a \left[2 b\left(-1+\sqrt{1-b^{2}}\right) \alpha+b^{4}(-1+\alpha) \alpha+4\left(1-\sqrt{1-b^{2}}\right) \alpha^{2}+b^{3}\left(\sqrt{1-b^{2}}+2 \alpha-\sqrt{1-b^{2}} \alpha\right)\right.\right.} \\
& \left.+b^{2} \alpha\left(1-\sqrt{1-b^{2}}-5 \alpha+3 \sqrt{1-b^{2}} \alpha\right)\right]+c\left(b^{4}(1-\alpha) \alpha+4\left(1-\sqrt{1-b^{2}}\right) \alpha^{2}+2 b\left(1-\sqrt{1-b^{2}}\right) \alpha(1+4 \alpha)\right. \\
p_{0}^{q q}= & \frac{\left.\left.+b^{2}\left[2\left(1+\sqrt{1-b^{2}}\right)+\alpha\left(3-3 \sqrt{1-b^{2}}-\alpha-\sqrt{1-b^{2}} \alpha\right)\right]+b^{3}\left\{2+\sqrt{1-b^{2}}+\alpha\left[2-3 \sqrt{1-b^{2}}-2\left(3-\sqrt{1-b^{2}}\right) \alpha\right]\right\}\right)\right]}{2(1+b)\left\{4\left(1-\sqrt{1-b^{2}}\right) \alpha^{2}+b^{2}(1-\alpha)\left[1+\sqrt{1-b^{2}}+\left(3-\sqrt{1-b^{2}}\right) \alpha\right]\right\}}, \\
& \left(a b\left\{b^{3}(-1+\alpha)+2\left(1-\sqrt{1-b^{2}}\right) \alpha^{2}-b^{2} \alpha\left[\sqrt{1-b^{2}}+\left(2-\sqrt{1-b^{2}}\right) \alpha\right]+b\left[1+\sqrt{1-b^{2}}-\left(1-\sqrt{1-b^{2}}\right) \alpha\right]\right\}\right. \\
& +c\left\{b^{4}(1-\alpha)+8\left(1-\sqrt{1-b^{2}}\right) \alpha^{2}+6 b\left(1-\sqrt{1-b^{2}}\right) \alpha^{2}+b^{3}\left[2\left(1+\sqrt{1-b^{2}}\right)+\left(4-3 \sqrt{1-b^{2}}\right) \alpha-\left(4-\sqrt{1-b^{2}}\right) \alpha^{2}\right]\right. \\
& \left.\left.+b^{2}\left[1+\sqrt{1-b^{2}}+5\left(1-\sqrt{1-b^{2}}\right) \alpha-2\left(3-\sqrt{1-b^{2}}\right) \alpha^{2}\right]\right\}\right) \\
p_{1}^{q q}= & \frac{2(1+b)\left\{4\left(1-\sqrt{1-b^{2}}\right) \alpha^{2}+b^{2}(1-\alpha)\left[1+\sqrt{1-b^{2}}+\left(3-\sqrt{1-b^{2}}\right) \alpha\right]\right\}}{} .
\end{aligned}
$$

\subsection{Price-Setting Framework}

In this subsection, we consider the situation wherein the strategic variables of firms 0 and 1 are their price levels.
The objective functions of firms 0 and 1 are given as follows:

$$
\begin{gathered}
V_{0}^{p p}\left(p_{0}, p_{1}\right)=W\left(p_{0}, p_{1}\right)=\frac{2 a^{2}(1-b)-4 a(1-b) c-p_{0}^{2}+2 b p_{0} p_{1}-p_{1}^{2}+2(1-b) c\left(p_{0}+p_{1}\right)}{2\left(1-b^{2}\right)}+m, \\
V_{1}^{p p}\left(p_{0}, p_{1}\right)=\pi_{1}\left(p_{0}, p_{1}\right)-\alpha \pi_{0}\left(p_{0}, p_{1}\right)=\frac{\left(p_{1}-c\right)\left[a(1-b)+b p_{0}-p_{1}\right)-\left(p_{0}-c\right)\left[a(1-b)-p_{0}+b p_{1}\right] \alpha}{1-b^{2}} .
\end{gathered}
$$

Firm 0 decides its price level in order to maximize $V_{0}^{p p}$, assuming that the reaction of the price level of firm 1 to the price level of firm 0 is given as follows:

$$
\frac{\partial p_{1}}{\partial p_{0}}=\delta_{0}^{p p} .
$$

On the other hand, firm 1 decides its price level in order to maximize $V_{1}^{p p}$ assuming that the reaction of the price level of firm 0 to the price level of firm 1 is given as fol lows:

$$
\frac{\partial p_{0}}{\partial p_{1}}=\delta_{1}^{p p} .
$$

The first-order conditions of firms 0 and 1 in the price-setting competition are given, and their real reaction functions are obtained as follows: ${ }^{9}$

From the real reaction of the price level of firm $i$ to the price level of firm $j$, we obtain the following result $(i, j=$

$$
\begin{aligned}
\frac{\partial V_{0}^{p p}}{\partial p_{0}}= & -\frac{p_{0}-b p_{0} \delta_{0}-(1-b) c\left(1+\delta_{0}\right)-p_{1}\left(b-\delta_{0}\right)}{1-b^{2}}=0 \Leftrightarrow p_{0}\left(p_{1}\right)=\frac{-p_{0}+b p_{0} \delta_{0}+(1-b) c\left(1+\delta_{0}\right)+p_{1}\left(b-\delta_{0}\right)}{1-b^{2}}, \\
& \frac{\partial V_{1}^{p p}}{\partial p_{1}}=\frac{a(1-b)+b p_{0}-p_{1}+\left(c-p_{1}\right)\left(1-b \delta_{1}\right)-\alpha\left[\left(a+c-2 p_{0}\right) \delta_{1}-b\left(c-p_{0}+a \delta_{1}-p_{1} \delta_{1}\right)\right]}{1-b^{2}}=0 \\
& \Leftrightarrow p_{1}\left(p_{0}\right)=\frac{c\left(1+b \alpha-b \delta_{1}-\alpha \delta_{1}\right)+a(1-b)\left(1-\alpha \delta_{1}\right)+p_{0}\left(b-b \alpha+2 \alpha \delta_{1}\right)}{2-b(1-\alpha) \delta_{1}}
\end{aligned}
$$

\footnotetext{
${ }^{9}$ The second-order conditions of firms 0 and 1 are satisfied.
} 
$0,1 ; i=j)$ :

$\frac{\partial p_{0}}{\partial p_{1}}=\frac{b-\delta_{0}}{1-b \delta_{0}}$, and $\frac{\partial p_{1}}{\partial p_{0}}=\frac{b-b \alpha+2 \alpha \delta_{1}}{2-b(1-\alpha) \delta_{1}}$, respectively.

The conditions of the consistency of the conjectural variations of firms 0 and 1 are, respectively

$$
\left\{\begin{array}{l}
\left(b-\delta_{0}\right) /\left(1-b \delta_{0}\right)=\delta_{1}, \\
\left(b-b \alpha+2 \alpha \delta_{1}\right) /\left[2-b(1+\alpha) \delta_{1}\right]=\delta_{0},
\end{array}\right.
$$

yielding

$$
\delta_{0}^{p p}=\frac{b^{2}(1-\alpha)+2\left(1+\sqrt{1-b^{2}}\right) \alpha}{b\left(1-\sqrt{1-b^{2}}+\alpha+\sqrt{1-b^{2}} \alpha\right.}, \quad \delta_{1}^{p p}=\frac{1-\sqrt{1-b^{2}}}{b} .
$$

The above values of firms 0 and 1 are the equilibrium consistent conjectures in the price-setting competition under the assumption that $\delta_{0}^{p p} \in(-1,1)$ and $\delta_{1}^{p p} \in(-1,1)$. Note that each firm's consistent conjectural variation in the price-setting competition is different from that in the quantity-setting competition..$^{10}$ Thus, the equilibrium price level and output level under the assumption that $\delta_{0}=\delta_{0}^{p p}$ and $\delta_{1}=\delta_{1}^{p p}$ are obtained as follows:

By summing up the equilibrium market outcomes and including the output and price levels of firms 0 and 1 between the quantity-setting competition and the pricesetting competition, we obtain the following proposition:

$$
\begin{aligned}
& {\left[a \left[2 b\left(-1+\sqrt{1-b^{2}}\right) \alpha+b^{4}(-1+\alpha) \alpha+4\left(1-\sqrt{1-b^{2}}\right) \alpha^{2}+b^{3}\left(\sqrt{1-b^{2}}+2 \alpha-\sqrt{1-b^{2}} \alpha\right)\right.\right.} \\
&\left.+b^{2} \alpha\left(1-\sqrt{1-b^{2}}-5 \alpha+3 \sqrt{1-b^{2}} \alpha\right)\right]+c\left(b^{4}(1-\alpha) \alpha+4\left(1-\sqrt{1-b^{2}}\right) \alpha^{2}+2 b\left(1-\sqrt{1-b^{2}}\right) \alpha(1+4 \alpha)\right. \\
& p_{0}^{p p}=\left.\left.+b^{2}\left[2\left(1+\sqrt{1-b^{2}}\right)+\alpha\left(3-3 \sqrt{1-b^{2}}-\alpha-\sqrt{1-b^{2}} \alpha\right)\right]+b^{3}\left\{2+\sqrt{1-b^{2}}+\alpha\left[2-3 \sqrt{1-b^{2}}-2\left(3-\sqrt{1-b^{2}}\right) \alpha\right]\right\}\right)\right] \\
& 2(1+b)\left\{4\left(1-\sqrt{1-b^{2}}\right) \alpha^{2}+b^{2}(1-\alpha)\left[1+\sqrt{1-b^{2}}+\left(3-\sqrt{1-b^{2}}\right) \alpha\right]\right\} \\
&\left(a b\left\{b^{3}(-1+\alpha)+2\left(1-\sqrt{1-b^{2}}\right) \alpha^{2}-b^{2} \alpha\left[\sqrt{1-b^{2}}+\left(2-\sqrt{1-b^{2}}\right) \alpha\right]+b\left[1+\sqrt{1-b^{2}}-\left(1-\sqrt{1-b^{2}}\right) \alpha\right]\right\}\right. \\
&+c\left\{b^{4}(1-\alpha)+8\left(1-\sqrt{1-b^{2}}\right) \alpha^{2}+6 b\left(1-\sqrt{1-b^{2}}\right) \alpha^{2}+b^{3}\left[2\left(1+\sqrt{1-b^{2}}\right)+\left(4-3 \sqrt{1-b^{2}}\right) \alpha-\left(4-\sqrt{1-b^{2}}\right) \alpha^{2}\right]\right. \\
&\left.\left.+b^{2}\left[1+\sqrt{1-b^{2}}+5\left(1-\sqrt{1-b^{2}}\right) \alpha-2\left(3-\sqrt{1-b^{2}}\right) \alpha^{2}\right]\right\}\right) \\
& p_{1}^{p p}= \frac{2(1+b)\left\{4\left(1-\sqrt{1-b^{2}}\right) \alpha^{2}+b^{2}(1-\alpha)\left[1+\sqrt{1-b^{2}}+\left(3-\sqrt{1-b^{2}}\right) \alpha\right]\right\}}{},
\end{aligned}
$$

and

$$
=\frac{(a-c)\left\{b^{3}(1-\alpha)+2 b\left(1-\sqrt{1-b^{2}}\right) \alpha+4\left(1-\sqrt{1-b^{2}}\right) \alpha^{2}+b^{2}\left[2\left(1+\sqrt{1-b^{2}}\right)+3\left(1-\sqrt{1-b^{2}}\right) \alpha+\left(3-\sqrt{1-b^{2}}\right) \alpha^{2}\right]\right\}}{2(1+b)\left\{4\left(1-\sqrt{1-b^{2}}\right) \alpha^{2}+b^{2}(1-\alpha)\left[1+\sqrt{1-b^{2}}+\left(3-\sqrt{1-b^{2}}\right) \alpha\right]\right\}},
$$

$$
=\frac{(a-c)\left\{b^{3}(1-\alpha) \alpha+8\left(1-\sqrt{1-b^{2}}\right) \alpha^{2}+2 b\left(1-\sqrt{1-b^{2}}\right) \alpha^{2}+b^{2}\left[1+\sqrt{1-b^{2}}+3\left(1-\sqrt{1-b^{2}}\right) \alpha-2\left(3-\sqrt{1-b^{2}}\right) \alpha^{2}\right]\right\}}{2(1+b)\left\{4\left(1-\sqrt{1-b^{2}}\right) \alpha^{2}+b^{2}(1-\alpha)\left[1+\sqrt{1-b^{2}}+\left(3-\sqrt{1-b^{2}}\right) \alpha\right]\right\}} .
$$

\footnotetext{
${ }^{10}$ As shown in Tanaka [8], in a private duopoly composed of two absolute profit maximizing firms, their consistent conjectural variations in the quantity-setting competition are different from those in the price-setting competition.
} 
Proposition 1. In a mixed duopoly with the consistent conjectural variations of both the welfare maximizing public firm and the relative profit maximizing private firm, the equilibrium outcomes in the quantity-setting competition including output and price levels, profit, consumer surplus, and social welfare, are equivalent to those in the price-setting competition.

Note that the statement of Proposition 1 is relevant to a standard mixed duopoly composed of one social welfare maximizing public firm and one absolute profit maximizing private firm since it includes the case of $\alpha=0$.

Thus, in a mixed duopoly with the consistent conjectural variations of both the welfare maximizing public firm and the relative profit maximizing private firm, we must pay attention to the fact that there is no advantage between the price-setting competition and the quantity-setting competition, since the equilibrium market outcomes in both the competitions are the same with each other.

\section{Concluding Remarks}

In this paper, we considered the equilibrium outcomes in a mixed duopoly with differentiated and substitutable goods and with firms' consistent conjectures, which are composed of one social welfare maximizing public firm and one relative profit maximizing private firm. Then, similar to the private duopolies composed of two absolute profit maximizing firms and of two relative profit maximizing firms shown in Tanaka [8], we show that the equilibrium outcomes in the quantity-setting competition are equivalent to those in the price-setting competition even in a mixed duopoly composed of one social welfare-maximizing public firm and one relative profit-maximizing private firm.

Finally, we indicate several topics that are left to our future studies. First, we must check whether or not the results obtained in this paper also hold given the assumptions of the general number of private firms and the general inverse and ordinary demand functions. Second, we should investigate the issue of capacity choice in a mixed duopoly with consistent conjectural variations, which is composed of one social welfare maximizing public firm and one relative profit maximizing private firm `a la Nakamura and Saito [14] and Nakamura and Saito [15]. These studies are left for future works.

\section{REFERENCES}

[1] T. Bresnahan, "Duopoly Models with Consistent Conjectures," American Economic Review, Vol. 71, No. 5, 1981, pp. 934-945.

[2] M. Perry, "Oligopoly and Consistent Conjectural Variations," Bell Journal of Economics, Vol. 13, No. 1, 1982, pp. 197-205. doi:10.2307/3003440

[3] M. Boyer and M. Moreaux, "Consistent versus Non-
Consistent Conjectures in Duopoly Theory: Some Examples," Journal of Industrial Economics, Vol. 32, No. 1, 1983, pp. 97-110. doi:10.2307/2097988

[4] Y. Tanaka, "Consistent Conjectures in Free Entry Oligopoly," Economics Letters, Vol. 17, No. 1-2, 1985, pp. 15-18. doi:10.1016/0165-1765(85)90118-1

[5] Y. Tanaka, "On Multiplicity of Consistent Conjectures in Free Entry Oligopoly," Economics Letters, Vol. 28, No. 2, 1985, pp. 109-115. doi:10.1016/0165-1765(88)90099-7

[6] Y. Tanaka, "Equivalance of Cournot and Bertrand Equilibria in Differentiated Duopoly under Relative Profit Maximization with Linear Demand," Economics Bulletin, Vol. 33, No. 2, 2013a, pp. 1479-1486.

[7] Y. Tanaka, "Irrelevance of the Choice of Strategic Variables in Duopoly under Relative Profit Maximization," Economics and Business Letters, Vol. 2, No. 2, 2013b, pp. 75-83.

[8] Y. Tanaka, "Irrelevance of Conjectural Variation in Duopoly under Relative Profit Maximization and Consistent Conjectures," 2013c (mimeo).

[9] M. E. Schaffer, "Are Profit Maximizers the Best Survivors?" Journal of Economic Behavior and Organization, Vol. 12, No. 1, 1989, pp. 29-45. doi:10.1016/0167-2681(89)90075-9

[10] F. Vega-Redondo, "The Evolution of Walrasian Behavior," Econometrica, Vol. 65 No. 2, 1997, pp. 375-384. doi: $10.2307 / 2171898$

[11] C. Lundgren, "Using Relative Profit Incentives to Prevent Collusion," Review of Industrial Organization, Vol. 11, No. 4, 1996, pp. 533-550. doi:10.1007/BF00157777

[12] L. Kockesen, E. A. Ok and R. Sethi, "The Strategic Advantage of Negatively Interdependent Preferences," Journal of Economic Theory, Vol. 92, No. 2, 2000, pp. 274-299. doi:10.1006/jeth.1999.2587

[13] T. Matsumura and N. Matsushima, "Competitiveness and Stability of Collusive Behavior," Bulletin of Economic Research, Vol. 64, Suppl. S1, 2012, pp. 22-31. doi:10.1111/j.1467-8586.2012.00439.x

[14] Y. Nakamura and M. Saito, "Capacity Choice in a Mixed Duopoly: The Relative Performance Approach," Theoretical Economics Letters, Vol. 3, No. 2, 2013a, pp. 124 133. doi:10.4236/tel.2013.32020

[15] Y. Nakamura and M. Saito, "Capacity Choice in a Price-Setting Mixed Duopoly: The Relative Performance Approach," Modern Economy, Vol. 4, No. 4, 2013b, pp. 273-280. doi:10.4236/me.2013.44031

[16] N. Singh and X. Vives, "Price and Quantity Competition in a Differentiated Duopoly," RAND Journal of Economics, Vol. 15, No. 4, 1984, pp. 546-554. doi: $10.2307 / 2555525$

[17] T. Matsumura and M. Okamura, "Competition and Privatization Policy: The Relative Performance Approach," 2010 (mimeo).

[18] C. Fershtman and K. Judd, "Equilibrium Incentives in Oligopoly," American Economic Review, Vol. 77, No. 5, 1987, pp. 927-940.

[19] S. D. Sklivas, "The Strategic Choice of Managerial In- 
centives," RAND Journal of Economics, Vol. 18, No. 3, 1987, pp. 452-458. doi:10.2307/2555609

[20] J. Vickers, "Delegation and the Theory of the Firm,"
Economic Journal, Vol. 95, No. 380, 1985, pp. 138-147. doi: $10.2307 / 2232877$ 